\title{
The patient voice: a survey of worries and anxieties during health system transition in HIV services in Vietnam
}

Shoko Matsumoto ${ }^{1 *}$ D , Hoai Dung Thi Nguyen ${ }^{2}$, Dung Thi Nguyen², Giang Van Tran ${ }^{2,3}$, Junko Tanuma ${ }^{1}$, Daisuke Mizushima', Kinh Van Nguyen ${ }^{2,3}$ and Shinichi Oka ${ }^{1}$

\begin{abstract}
Background: Vietnam is shifting toward integrating HIV services into the public health system using social health insurance (SHI), and the HIV service delivery system is becoming decentralized. The study aim was to investigate current SHI coverage and patients' perspectives on this transition.

Methods: A survey of 1348 HIV-positive patients on antiretroviral therapy (aged $\geq 18$ years) was conducted at an HIV outpatient clinic at a central-level hospital in Hanoi, Vietnam, in October and November 2018. Insurance coverage, reasons for not having a SHI card, perceived concerns about receiving HIV services in SHI-registered local health facilities, and willingness to continue regularly visiting the current hospital were self-reported. Logistic regression analyses were performed to analyze factors associated with not having a SHI card and having concerns about receiving HIV services in SHI-registered hospitals/clinics.

Results: $\mathrm{SHI}$ coverage was $78.0 \%$. The most frequently reported reason for not having a SHI card was that obtaining one was burdensome, followed by lack of information on how to obtain a card, and financial problems. Most patients (86.6\%) had concerns about receiving HIV services at SHI-registered local health facilities, and disclosure of HIV status to neighbors and low quality of HIV services were the main concerns reported. Participants aged $<40$ years old and unmarried were more likely to report lack of SHI cards, and women and those aged $\geq 40$ years were more likely to have concerns. However, $91.4 \%$ of patients showed willingness to continue regular visits to the current hospital.

Conclusions: Although SHI coverage has been rapidly improving among HIV patients, most participants had concerns about the current system transition in Vietnam. In response to their voiced concerns, strengthening the link between higher-level and lower-level facilities may help to ensure good quality HIV services at all levels while mitigating patients' worries and anxieties.
\end{abstract}

Keywords: Social health insurance, HIV, Vietnam, Health system

\section{Background}

Vietnam's HIV epidemic has stabilized after peaking in the early 2000s. However, HIV still remains a public health threat in Vietnam, with an estimated 220,000 to 280,000 people living with HIV (PLHIV) and 11,000 new HIV infections in 2017 [1]. The HIV epidemic is concentrated in key populations, including people who inject

\footnotetext{
* Correspondence: smatsumo@acc.ncgm.go.jp

${ }^{1}$ AIDS Clinical Center, National Center for Global Health and Medicine, 1-21-1, Toyama, Shinjuku, Tokyo 162-8655, Japan

Full list of author information is available at the end of the article
}

drugs; 45\% of new infections in 2013 occurred among men who shared needles when injecting drugs [2].

Over the last two decades, large international cooperation networks have supported antiretroviral therapy (ART) in Vietnam, including, but not limited to, the United States' President's Emergency Plan for AIDS Relief (PEPFAR) and the Global Fund to Fight AIDS, Tuberculosis and Malaria. However, as Vietnam's economy has grown, these organizations have been phasing out their activities in Vietnam; the largest source of international aid, the PEPFAR program,

(c) The Author(s). 2020 Open Access This article is distributed under the terms of the Creative Commons Attribution 4.0 International License (http://creativecommons.org/licenses/by/4.0/), which permits unrestricted use, distribution, and reproduction in any medium, provided you give appropriate credit to the original author(s) and the source, provide a link to the Creative Commons license, and indicate if changes were made. The Creative Commons Public Domain Dedication waiver (http://creativecommons.org/publicdomain/zero/1.0/) applies to the data made available in this article, unless otherwise stated. 
will end its direct support for ART by the end of 2019.

To sustainably finance the maintenance and expansion of HIV care and treatment, Vietnam is now shifting toward integrating HIV services into the public health system using social health insurance (SHI). After 3 years of piloting voluntary health insurance schemes in some provinces, Vietnam introduced social health insurance to all provinces in 1992 to cover formal-sector workers and pensioners. With the goal of universal coverage, the Vietnamese government issued the first SHI law (Decree No. 63) in 2008, which expanded coverage to people experiencing poverty by fully subsidizing premiums for this group and informal-sector workers. To increase universal health coverage, the SHI law was revised in 2014 and SHI became mandatory for all citizens [3]. According to a report from the Vietnam Social Security (VSS), Vietnam has achieved a remarkable increase in SHI coverage; the number of health insurance card holders reached 83.5 million (88.5\% of the total population) in 2019 [4]. As part of the transition from donor-based to SHI-based HIV service delivery, a Prime Minister's Decision (No. 2188/QD-TTg) was issued in 2016 that introduced a new goal of $100 \%$ SHI coverage (hereafter referred to "universal SHI coverage") for PLHIV by 2020. As a result, SHI coverage for PLHIV improved dramatically from $40 \%$ in 2014 [5] to more than $85 \%$ in 2018 [6].

The HIV finance transition includes the move from a centralized to a decentralized HIV service delivery system. As ART has been provided free of charge mainly owing to the support of international donors, many HIV patients are currently served by central urban hospitals and receive better quality of care. However, to be eligible for SHI coverage for HIV services, PLHIV must obtain a SHI card that can be used only in a SHI-registered health facility near their registered residence or in samelevel facilities of a SHI-registered hospital/clinic in the same province. Although SHI coverage and decentralization improve access to HIV services at lower levels of care, they may pose new challenges for PLHIV who have been receiving ART free of charge at higherlevel hospitals [7]. For example, many district- and commune-level HIV clinics have insufficient capacity and experience for HIV care and treatment, so that essential laboratory tests to monitor ART effectiveness, such as the viral load (VL) test, are often not available. Additionally, most PLHIV, except those experiencing poverty, will be expected to pay up to $20 \%$ of costs in copayments [5]. Furthermore, owing to the lack of privacy of health care, PLHIV may face difficulties keeping their HIV status confidential if they regularly visit local HIV clinics [8, 9].
The above-mentioned transition seems to be progressing rapidly owing to strong political commitments rather than patient-centered approaches [10]. To achieve universal health coverage and to ensure a decentralized service delivery system that meets the needs of PLHIV, it is important to listen carefully to patients' voices to safeguard the continuation of effective, local HIV treatment, and to prevent patients from worrying about the new health system. Therefore, this study was designed to investigate the current SHI coverage situation and patients' perspectives on the transition in the HIV service delivery system, and to provide possible solutions to reduce the negative impacts of the transition.

\section{Materials and methods Study design and study subjects}

We conducted a self-administered questionnaire survey using a hospital-based cohort of PLHIV on ART (aged $\geq 18$ years) in October and November 2018. This cohort, the so-called "Hanoi cohort," was established in 2007 at the HIV outpatient clinic at the National Hospital for Tropical Diseases (NHTD), one of the largest central-level HIV clinics in Hanoi, Vietnam. At the time of the survey, the Hanoi cohort participants were still regularly receiving ART and other HIV services in NHTD, and they were invited to complete the survey during their regular consultations. Individuals who provided informed consent participated in the survey on the same day as their consultation.

To develop the questionnaire used in this survey, an expert panel was formed by HIV/AIDS specialists, including HIV clinicians, social workers, and a social epidemiologist. The panel developed the questionnaire and response options using information from previous relevant reports $[10,11]$ and experiences in day-to-day clinical practice.

\section{Measurements \\ SHI coverage}

SHI coverage was evaluated by asking whether participants had a valid SHI card. The hospital/clinic level (i.e., national, provincial, district, or commune) was also recorded. Participants who did not have a SHI card were asked to provide reasons using the question "Why don't you have a SHI card?" Possible responses were "I cannot afford it," "It feels like a burden," "I do not know how to get one," and "Other." Participants could select as many responses as were applicable. If they selected "Other," they were able to provide reasons (although this was optional). 


\section{Concerns about receiving HIV services in SHI-registered hospitals/clinics}

The presence of perceived concerns about receiving HIV services in SHI-registered hospitals/clinics was evaluated with the question "Do you have any concerns about receiving HIV services in your SHI-registered health facilities?"; possible responses were "yes" or "no." Participants with perceived concerns were then asked about the nature of their concerns; possible responses were "Disclosure of HIV status to neighbors," "Low quality of HIV services," "Fear of not getting along with unfamiliar medical staffs," and "Other." Participants could select as many items as were applicable. If they selected "Other," they were able to provide reasons (although this was optional).

\section{Willingness to regularly visit the current hospital}

Patients' willingness to regularly visit their current hospital was evaluated with the question "Are you willing to continue visiting NHTD every 6 months for VL monitoring after being transferred to the SHI-registered local hospital/clinic?" Possible responses were "yes" or "no." Participants who responded "yes" were further asked about their reasons, and possible responses were "I think that VL monitoring is beneficial for me," "I want to keep in contact with NHTD," "I want to meet staffs here," and "Other." Participants could select as many items as were applicable. If they selected "Other," they were able to provide reasons (although this was optional).

\section{Demographics and HIV-related factors}

The following data on demographic and HIV-related factors were collected: sex, age, history of injection drug use (IDU), duration of receiving HIV services at NHTD, marital status, residence, educational attainment, employment, individual income, and disclosure of HIV status. Age was divided into two categories using the median value: $<40$ years and $\geq 40$ years. History of IDU was divided into two categories: IDU (ever used injection drugs) and non-IDU (never used injection drugs). Duration of receiving HIV services at NHTD was divided into the following categories using 25th and 75th percentile values: $<5$ years, $5-9$ years, and $\geq 10$ years. Marital status was divided into two categories: married and not married (including divorced or widowed). Residence was divided into three categories: Hanoi, provinces around Hanoi, and other provinces. Provinces around Hanoi included eight provinces bordered by Hanoi and regarded as neighbor provinces. "Other provinces" referred to provinces that are a substantial traveling distance from Hanoi. Employment was categorized as not employed, employed, or retired. Individual income was divided into the following categories according to monthly income per capita in 2012, as reported by the
General Statistics Office of Vietnam [12]: low $(<1,500$, 000 Vietnamese dong [VND]), middle (1,500,000-4,999, 999 VND), and high $(\geq 5,000,000$ VND) (1 VND = 0.000043 USD). Disclosure of HIV status was evaluated dichotomously. Educational attainment was divided into three groups based on the fact that the primary school enrollment rate reached over $90 \%$ and the tertiary education enrollment rate reached 25 to $30 \%$ in 2018 [13]: low (never went to school, primary school, or junior high school), middle (high school), and high (vocational school/college or university).

\section{Statistical analysis}

Baseline characteristics were summarized for all participants. We calculated SHI coverage, the proportion of participants who had concerns about receiving HIV services in SHI-registered hospitals/clinics, and the proportion of participants willing to regularly visit the current hospital, and then summarized the reasons for not having a SHI card, the nature of concerns, and reasons for the willingness to regularly attend the current hospital. Logistic regression analyses were then performed to analyze the factors associated with "not having a SHI card" and "having concerns about receiving HIV services in SHI-registered hospitals/clinics," and crude and multivariate-adjusted odds ratios (OR) were calculated. In the multivariate analyses, we used variables that had $p$-values $<0.05$ in the univariate analysis for adjustment. As a sensitivity analysis, we conducted multivariate analyses using a stepwise selection method for all variables (inclusion and exclusion criteria $=0.2$ for each).

All analyses were performed using SAS 9.4 software (SAS Institute Inc., Cary, NC, USA). All tests were twosided, with the significance level set at 5\%. Missing data were excluded from the analyses.

\section{Results \\ Study participants}

Since October 2007, 1820 patients had registered for the Hanoi cohort, and 1348 were still enrolled and underwent follow-up in October and November 2018. All patients agreed to participate in the survey (response rate: $100 \%)$.

Table 1 shows the respondents' characteristics. In all, $58.3 \%$ of participants were males. The median age (interquartile range) was 40 (36-45) years. Furthermore, $22.9 \%$ of participants had a history of IDU, and nearly 90\% had been receiving HIV services at NHTD for 5 years or longer. Approximately one-third lived in provinces far from Hanoi (there was even one participant who lived in Hue, a city in the middle of Vietnam). 
Table 1 Participant characteristics2

\begin{tabular}{|c|c|}
\hline & n (\%) \\
\hline$\overline{A l l}$ & $1348(100.0)$ \\
\hline \multicolumn{2}{|l|}{ Sex } \\
\hline Male & $786(58.3)$ \\
\hline Female & $562(41.7)$ \\
\hline \multicolumn{2}{|l|}{ Age } \\
\hline Median (IQR) & $40(36,45)$ \\
\hline$<40$ years old & $612(45.4)$ \\
\hline$\geq 40$ years old & $736(54.6)$ \\
\hline \multicolumn{2}{|l|}{ History of IDU } \\
\hline No & $1040(77.2)$ \\
\hline Yes & $308(22.9)$ \\
\hline \multicolumn{2}{|c|}{ Duration of receiving HIV services at NHTD } \\
\hline$<5$ years & $154(11.4)$ \\
\hline $5-9$ years & $910(67.5)$ \\
\hline$\geq 10$ years & $284(21.2)$ \\
\hline \multicolumn{2}{|l|}{ Marital status } \\
\hline Married & $974(72.3)$ \\
\hline Not married & $139(10.3)$ \\
\hline N/A & $235(17.4)$ \\
\hline \multicolumn{2}{|l|}{ Residence } \\
\hline Hanoi & $607(45.0)$ \\
\hline Provinces around Hanoi & $259(19.2)$ \\
\hline Other provinces & $482(35.8)$ \\
\hline \multicolumn{2}{|l|}{ Educational attainment ${ }^{a}$} \\
\hline Low & $291(21.6)$ \\
\hline Middle & $345(25.6)$ \\
\hline High & $477(35.4)$ \\
\hline N/A & $235(17.4)$ \\
\hline \multicolumn{2}{|l|}{ Employment } \\
\hline Not employed & $234(17.4)$ \\
\hline Employed & $821(60.9)$ \\
\hline Retired & $54(4.0)$ \\
\hline N/A & $239(17.7)$ \\
\hline \multicolumn{2}{|l|}{ Individual income ${ }^{b}$} \\
\hline Low & 264 (19.6) \\
\hline Middle & $527(39.1)$ \\
\hline High & $259(19.2)$ \\
\hline N/A & $298(22.1)$ \\
\hline \multicolumn{2}{|l|}{ Disclosure of HIV status } \\
\hline No & $57(4.2)$ \\
\hline Yes & $1056(78.3)$ \\
\hline N/A & $235(17.4)$ \\
\hline
\end{tabular}

$N / A$ missing value, IDU injection drug use, IQR interquartile range, NHTD National Hospital for Tropical Diseases

aEducational attainment: low: never went to school, primary school, or junior high school; middle: high school; high: vocational school/ college or university

${ }^{b}$ Individual income: low: < 1,500,000 VND; middle: 1,500,000-

4,999,999 VND; high: $\geq 5,000,000$ VND
SHI coverage and reasons for not having a SHI card

In total, 1051 (78.0\%) participants had a SHI card; of these, $35.3 \%$ were registered at district-level hospitals/ clinics and $21.4 \%$ at commune-level hospitals/clinics (Fig. 1). Of the 187 participants who did not have a SHI card, the most frequently reported reason was that obtaining a card "felt burdensome" (44.4\%), followed by "don't know how to get it" (20.9\%) and "cannot afford it" (17.1\%). Some other reasons reported were "fear of revealing HIV status" and "don't feel that it's necessary" (Fig. 2).

\section{Concerns about receiving HIV services in SHI-registered hospitals/clinics}

In total, 1167 (86.6\%) participants had concerns about receiving HIV services in SHI-registered hospitals/ clinics. Of these, $84.2 \%$ were concerned about disclosure of their HIV status to neighbors and $53.0 \%$ were concerned about the low quality of HIV services. Fear of not getting along with unfamiliar medical staffs was less frequently reported (14.8\%). Some other concerns reported were "not wishing to change hospital" and "influence on work or family" (Fig. 3).

\section{Willingness to regularly visit the current hospital}

There were 1232 (91.4\%) participants who were willing to continue visiting NHTD after being transferred to SHI-registered local hospitals/clinics. The most frequently reported reason for their willingness was "I want to keep in contact with NHTD" (81.5\%) followed by "I think that VL monitoring is beneficial for me" (79.9\%) and "I want to meet staffs here" (58.9\%) (Fig. 4).

Factors associated with not having a SHI card and having concerns about receiving HIV services in SHI-registered hospitals/clinics

Table 2 shows ORs and 95\% confidence intervals (95\% CI) for the univariate and multivariate logistic regression models with not having a SHI card as the outcome variable.

In the univariate model, age $(<40$ years old $)(\mathrm{OR}=$ 1.48, 95\% CI: $1.09-2.03$ vs. $\geq 40$ years old) and not being married (OR $=1.74,95 \% \mathrm{CI}$ : $1.09-2.77$ vs. being married) were significantly associated with not having a SHI card. In the multivariate model, both age ( $<40$ years old $)$ ( $\mathrm{OR}=1.46,95 \% \mathrm{CI}: 1.02-2.08$ vs. $\geq 40$ years old) and not being married $(\mathrm{OR}=1.64,95 \% \mathrm{CI}: 1.02-2.62$ vs. being married) remained significant, which was consistent with the results of the multivariate model using the stepwise selection method.

Table 3 shows ORs and 95\% CIs for the univariate and multivariate logistic regression models with having concerns about receiving HIV services in SHI-registered hospitals/clinics as the outcome variable. In the 


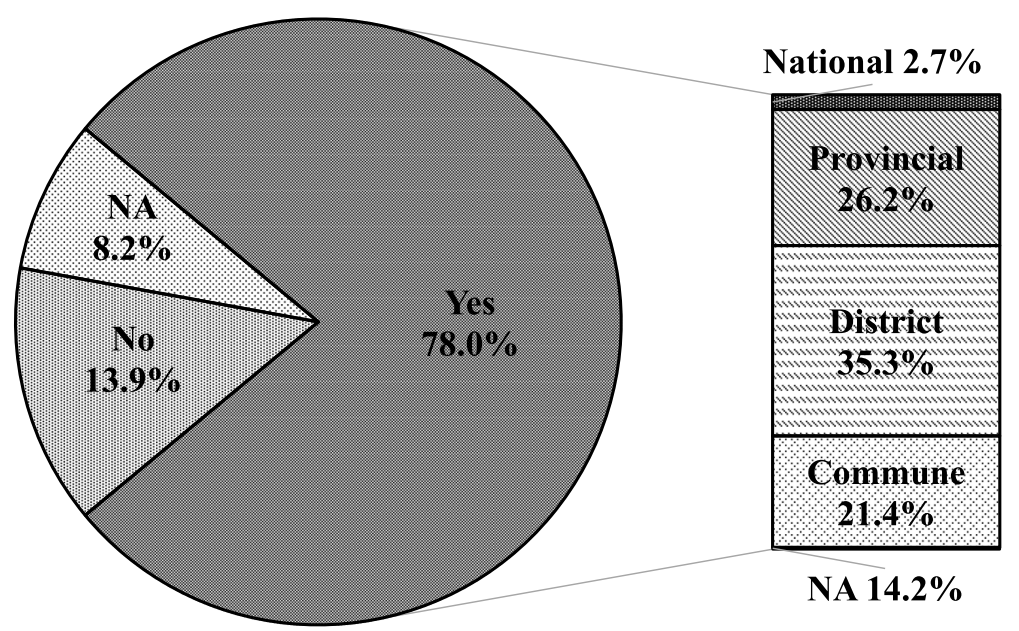

Fig. $1 \mathrm{SHI}$ coverage and level of SHI-registered facilities. NA: data are not available. SHI: social health insurance

univariate model, being female $(\mathrm{OR}=2.05,95 \% \mathrm{CI}$ : $1.45-2.89$ vs. male), age ( $\geq 40$ years old) $(\mathrm{OR}=1.39,95 \%$ CI: $1.02-1.90$ vs. < 40 years old), non-IDU (OR $=1.68$, 95\% CI: 1.19-2.37 vs. IDU), and being married (OR = 1.88, 95\% CI: $1.19-2.95$ vs. not being married) were significantly associated with having concerns about receiving HIV services. Of these, female sex $(\mathrm{OR}=2.02,95 \%$ CI: $1.33-3.08$ vs. male) and age ( $\geq 40$ years old) $(\mathrm{OR}=$ 1.46, 95\% CI: $1.02-2.08$ vs. < 40 years old) remained significant in the multivariate model, which is consistent with the results of the sensitivity analysis using the stepwise selection method.

\section{Discussion}

In this study, we evaluated patients' perspectives on the current transition of the HIV service delivery system in Vietnam. The SHI coverage was $78.0 \%$; over half the participants were SHI-registered at district- or communelevel clinics. Most participants had concerns about receiving HIV services in SHI-registered hospitals/clinics; the most frequently reported concerns were disclosure of HIV status to neighbors and low quality of HIV services. Over $90 \%$ of participants were willing to continue regularly visiting NHTD after being transferred to SHIregistered local clinics.

\section{Toward universal SHI coverage}

The transition of HIV finance is not an issue only in Vietnam. As international funding decreases, many lowand middle-income countries are now making efforts to increase domestic resources to fill the gap [14, 15]. In 2018, approximately $56 \%$ of the total resources for HIV in low- and middle-income countries were from domestic sources [16]. Although challenging for those countries, a shift toward domestic funding has advantages in terms of ownership, accountability, and sustainability of the national HIV response [17].

At NHTD, one of the largest HIV clinics in Hanoi, the SHI coverage was $78 \%$, indicating that SHI enrollment has been rapidly progressing (40\% in 2014 [5]),

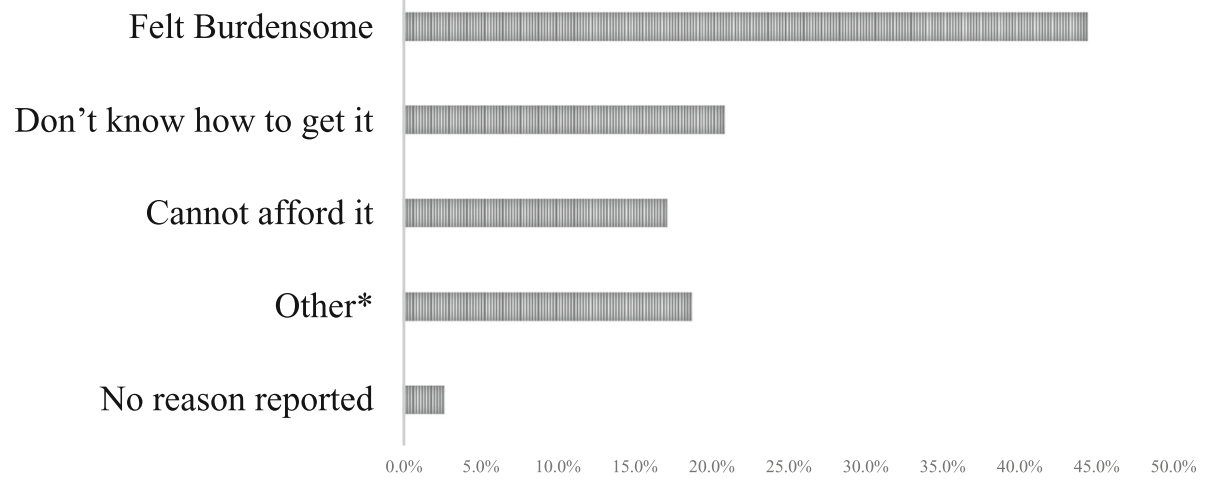

Fig. 2 Reasons for not having a SHI card. *Other $(n=35)$ includes "fear of HIV disclosure" (7), "feeling no necessity" (4), "just changed jobs" (3), "no time" (2), "forgot" (1), and "NA" (18). SHI: social health insurance 


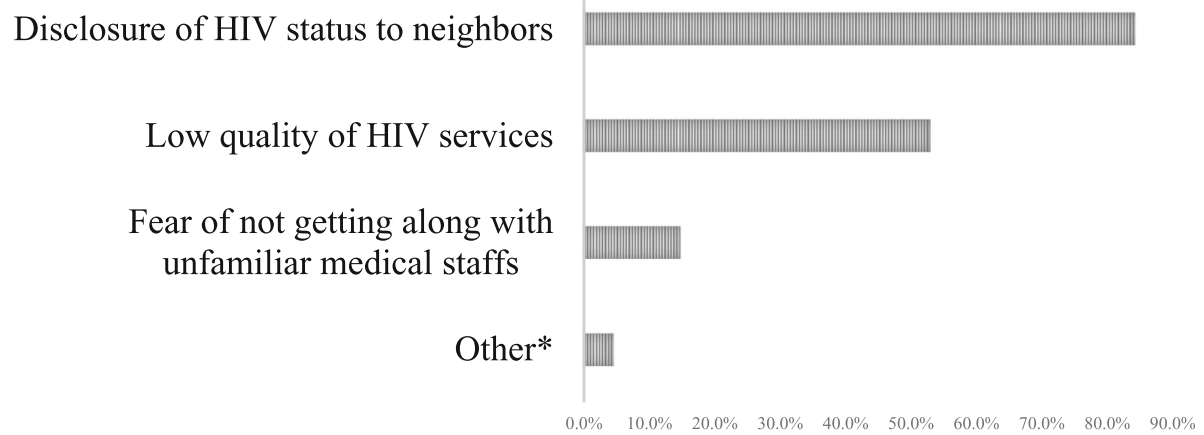

Fig. 3 Concerns about receiving HIV services in SHI-registered hospitals/clinics. *Other $(n=54)$ includes "not wishing to change hospital" (33), "influence on work or family" (17), and "inconvenience" (4). SHI: social health insurance

but that universal SHI coverage has not been reached. Although previous reports have highlighted financial burden as the main barrier to SHI access $[11,18]$, in this study, the most frequently reported reasons for not having a SHI card were that obtaining one was burdensome and there was a lack of information about accessing SHI, rather than financial problems. In addition, two finance-related variables (individual income and employment) were not associated with lack of a SHI card in the logistic regression analyses. Various recent policies and schemes introduced by central and local government (e.g., subsidies for premiums for people living in poverty and near-poverty, allocation of local budgets for purchasing SHI cards) might have successfully contributed to the expansion of SHI. This interpretation should be tested in other settings, as our study participants at NHTD may be receiving better financial support from local government and other authorities; such support may vary between provinces depending on their financial resources and commitment to HIV prevention and control.

Feeling that it was burdensome to obtain a SHI card and lacking information on how to obtain a SHI card were the most frequently reported reasons for not having one, and younger age ( $<40$ years old) and being unmarried were identified as possible risk factors. A burdensome feeling could arise for various reasons, including complicated administrative procedures for SHI registration, long waiting times, or feeling that a card is not necessary [11]. As SHI cards are issued based on residential information, disclosure of HIV status to others at the time of obtaining a card may be an additional reason for not having one. Alternatively, the reported lack of information about obtaining SHI cards may reflect patient lack of interest in SHI, as well as problems related to availability and accessibility of information. In particular, it may be difficult for younger people to understand the benefits of SHI, and unmarried persons might be less motivated to enroll into SHI. As previously suggested, providing adequate information about SHI could encourage the enrollment of PLHIV in SHI [7, 11, 19]. In a previous study, we found that family is often the only and the strongest supporter of PLHIV [20]. Raising awareness of the necessity and benefits of SHI, especially among younger and unmarried individuals,

\section{Wish to keep in contact with NHTD}

VL monitoring is beneficial

Wish to meet NHTD staff
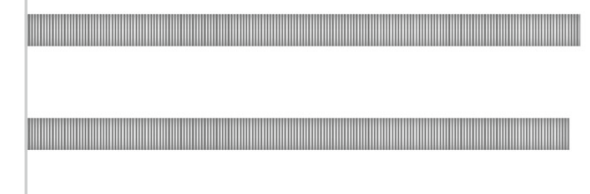

Other*

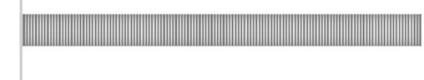

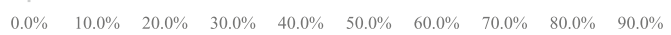

Fig. 4 Reasons for being willing to regularly visit NHTD. *Other $(n=41)$ includes "not wishing to change hospital" (16), "satisfied with quality of service at NHTD" (15), "convenience" (5), "fear of HIV disclosure" (3), and other (2). NHTD: National Hospital for Tropical Diseases; SHI: social health insurance; VL: viral load 
Table 2 ORs and 95\% Cls for not having a SHI card: regression results

\begin{tabular}{|c|c|c|c|c|}
\hline & \multicolumn{2}{|l|}{ Univariate model } & \multicolumn{2}{|c|}{$\begin{array}{l}\text { Multivariate model }{ }^{a} \\
(n=1020)\end{array}$} \\
\hline & OR $(95 \% \mathrm{Cl})$ & $p$-value & OR $(95 \% \mathrm{Cl})$ & $p$-value \\
\hline \multicolumn{5}{|l|}{ Sex } \\
\hline Male & 1.00 & 0.21 & & \\
\hline Female & $0.82(0.59-1.12)$ & & & \\
\hline \multicolumn{5}{|l|}{ Age } \\
\hline$<40$ years old & $1.48(1.09-2.03)$ & 0.01 & $1.46(1.02-2.08)^{d}$ & 0.04 \\
\hline$\geq 40$ years old & 1.00 & & 1.00 & \\
\hline \multicolumn{5}{|l|}{ History of IDU } \\
\hline No & $1.35(0.90-2.01)$ & 0.14 & & \\
\hline Yes & 1.00 & & & \\
\hline \multicolumn{5}{|c|}{ Duration of receiving HIV services at NHTD } \\
\hline$<5$ years & 1.00 & 0.20 & & \\
\hline $5-9$ years & $0.92(0.57-1.48)$ & & & \\
\hline$\geq 10$ years & $0.64(0.36-1.14)$ & & & \\
\hline \multicolumn{5}{|l|}{ Marital status } \\
\hline Married & 1.00 & 0.02 & 1.00 & 0.04 \\
\hline Not married & $1.74(1.09-2.77)$ & & $1.64(1.02-2.62)^{d}$ & \\
\hline \multicolumn{5}{|l|}{ Residence } \\
\hline Hanoi & 1.00 & 0.31 & & \\
\hline Provinces around Hanoi & $0.99(0.66-1.48)$ & & & \\
\hline Other provinces & $0.76(0.53-1.09)$ & & & \\
\hline \multicolumn{5}{|l|}{ Educational attainment ${ }^{\mathrm{b}}$} \\
\hline Low & $0.70(0.44-1.12)$ & 0.23 & & \\
\hline Middle & $1.05(0.71-1.57)$ & & & \\
\hline High & 1.00 & & & \\
\hline \multicolumn{5}{|l|}{ Employment } \\
\hline Not employed & $1.13(0.74-1.72)$ & 0.32 & & \\
\hline Employed & 1.00 & & & \\
\hline Retired & $0.49(0.17-1.39)$ & & & \\
\hline \multicolumn{5}{|l|}{ Individual income ${ }^{c}$} \\
\hline Low & $1.12(0.66-1.90)$ & 0.59 & & \\
\hline Middle & $1.26(0.80-1.97)$ & & & \\
\hline High & 1.00 & & & \\
\hline \multicolumn{5}{|l|}{ Disclosure of HIV status } \\
\hline No & $1.91(1.00-3.64)$ & 0.05 & & \\
\hline Yes & 1.00 & & & \\
\hline
\end{tabular}

OR odds ratio, 95\% Cl 95\% confidence interval, IDU injection drug use, NHTD National Hospital for Tropical Diseases, SHI social health insurance

${ }^{a}$ Variables with $p$-values $<0.05$ in the univariate analysis were used for adjustment

bEducational attainment: low: never went to school, primary school, or junior high school; middle: high school; high: vocational school/college or university

Individual income: low: <1,500,000 VND; middle: 1,500,000-4,999,999 VND; high: $\geq 5,000,000$ VND

${ }^{\mathrm{d}}$ Age ( $<40$ years old) $(\mathrm{OR}=1.47,95 \% \mathrm{Cl}: 1.02-2.12$ vs. $\geq 40$ years old) and not being married ( $\mathrm{OR}=1.66,95 \% \mathrm{Cl}: 1.01-2.72$ vs. being married) were associated with not having a SHI card ( $p$-values of 0.040 and 0.045 , respectively) in the multivariate model using stepwise selection method for all variables (inclusion and exclusion criteria $=0.2$ for each)

and providing support tailored to individual needs (e.g., the most convenient way to register for SHI) for both patients and family could enhance the understanding of SHI enrollment and patients' willingness to join SHI and help to achieve universal SHI coverage. 
Table 3 ORs and 95\% Cls for having concerns about HIV services in SHI-registered hospitals/clinics: regression results

\begin{tabular}{|c|c|c|c|c|}
\hline & \multicolumn{2}{|l|}{ Univariate model } & \multicolumn{2}{|c|}{$\begin{array}{l}\text { Multivariate model } \\
(n=1113)\end{array}$} \\
\hline & $\overline{\mathrm{OR}}(95 \% \mathrm{Cl})$ & $p$-value & $\overline{\mathrm{OR}}(95 \% \mathrm{Cl})$ & $p$-value \\
\hline \multicolumn{5}{|l|}{ Sex } \\
\hline Male & 1.00 & $<0.001$ & 1.00 & $<0.01$ \\
\hline Female & $2.05(1.45-2.89)$ & & $2.02(1.33-3.08)^{d}$ & \\
\hline \multicolumn{5}{|l|}{ Age } \\
\hline$<40$ years old & 1.00 & 0.04 & 1.00 & 0.04 \\
\hline$\geq 40$ years old & $1.39(1.02-1.90)$ & & $1.46(1.02-2.08)^{d}$ & \\
\hline \multicolumn{5}{|l|}{ History of IDU } \\
\hline No & $1.68(1.19-2.37)$ & $<0.01$ & $1.05(0.68-1.61)$ & 0.84 \\
\hline Yes & 1.00 & & 1.00 & \\
\hline \multicolumn{5}{|c|}{ Duration of receiving HIV services at NHTD } \\
\hline$<5$ years & 1.00 & 0.27 & & \\
\hline $5-9$ years & $1.22(0.76-1.94)$ & & & \\
\hline$\geq 10$ years & $1.58(0.90-2.79)$ & & & \\
\hline \multicolumn{5}{|l|}{ Marital status } \\
\hline Married & $1.88(1.19-2.95)$ & 0.01 & $1.56(0.98-2.49)$ & 0.06 \\
\hline Not married & 1.00 & & 1.00 & \\
\hline \multicolumn{5}{|l|}{ Residence } \\
\hline Hanoi & 1.00 & 0.60 & & \\
\hline Provinces around Hanoi & $1.07(0.70-1.63)$ & & & \\
\hline Other provinces & $1.20(0.84-1.71)$ & & & \\
\hline \multicolumn{5}{|l|}{ Educational attainment ${ }^{\text {b }}$} \\
\hline Low & $0.72(0.47-1.10)$ & 0.22 & & \\
\hline Middle & $0.74(0.49-1.11)$ & & & \\
\hline High & 1.00 & & & \\
\hline \multicolumn{5}{|l|}{ Employment } \\
\hline Not employed & $0.94(0.62-1.43)$ & 0.84 & & \\
\hline Employed & 1.00 & & & \\
\hline Retired & $1.24(0.52-2.96)$ & & & \\
\hline \multicolumn{5}{|l|}{ Individual income ${ }^{c}$} \\
\hline Low & $0.80(0.47-1.35)$ & 0.70 & & \\
\hline Middle & $0.87(0.55-1.38)$ & & & \\
\hline High & 1.00 & & & \\
\hline \multicolumn{5}{|l|}{ Disclosure of HIV status } \\
\hline No & 1.00 & 0.35 & & \\
\hline Yes & $0.71(0.35-1.44)$ & & & \\
\hline \multicolumn{5}{|c|}{ Level of SHI-registered hospital/clinic } \\
\hline National & 1.00 & 0.52 & & \\
\hline Provincial & $1.71(0.67-4.37)$ & & & \\
\hline District & $1.34(0.53-3.34)$ & & & \\
\hline Commune & $1.21(0.47-3.08)$ & & & \\
\hline Unknown & $0.60(0.05-6.79)$ & & & \\
\hline
\end{tabular}

OR odds ratio, 95\% Cl 95\% confidence interval, IDU injection drug use, NHTD National Hospital for Tropical Diseases, SHI social health insurance ${ }^{a}$ Variables with $p$-values $<0.05$ in the univariate analysis were used for adjustment

beducational attainment: low: never went to school, primary school, or junior high school; middle: high school; high: vocational school/college or university

Individual income: low: <1,500,000 VND; middle: 1,500,000-4,999,999 VND; high: $\geq 5,000,000$ VND

${ }^{d}$ Being female $(\mathrm{OR}=2.46,95 \% \mathrm{Cl}: 1.56-3.88$ vs. male) and age ( $\geq 40$ years old) $(\mathrm{OR}=1.58,95 \% \mathrm{Cl}: 1.04-2.40$ vs. $<40$ years old $)$ were associated with having concerns about receiving HIV services in SHI-registered hospitals/clinics ( $p$-values $<0.001$ and 0.03 , respectively) in the multivariate model using stepwise selection method for all variables (inclusion and exclusion criteria $=0.2$ for each) 
Patients' worries and anxieties during decentralization HIV stigma in the community

Participants' biggest concern about the decentralization of the HIV service delivery system was disclosure of HIV status to neighbors. In Vietnam, the HIV epidemic is concentrated among high-risk groups (e.g., IDU and sex workers) and many PLHIV live with substantial HIV stigma [21-23]. Over half of the study participants live outside Hanoi, and seeking HIV services far from home is a way of keeping their HIV status confidential and avoiding the negative consequences of disclosure (e.g., effects on work and family). It is well known that HIVrelated stigma is the main barrier to accessing HIV services [24, 25]. Therefore, the Vietnamese Ministry of Health issued a stigma reduction guideline in health care settings in 2017 and encouraged HIV clinics to develop an action plan for stigma reduction. However, PLHIV experience stigma from their community more frequently than from health care providers [9].

Over the past decade, there has been remarkable progress in research on interventions for stigma reduction, and an increase in the number and quality of intervention strategies [26]. Many research interventions have focused not only on PLHIV and health care workers, but also on local government, non-governmental organizations, community leaders or members, students, family, and women [26, 27]. Some researchers have suggested that interventions that combine multiple strategies (e.g., information-based approaches, skills building, counseling/support, and contact with affected groups) to address multiple stigma domains (e.g., drivers, facilitators, intersecting stigmas, and manifestations of stigma) may be more effective [26-28]. During the HIV service delivery transition, policymakers in Vietnam need to learn lessons from other countries and focus on expanding stigma reduction activities in various fields, to ensure that PLHIV can receive local HIV services without experiencing stigma.

Low quality of health services at lower-level health facilities Notably, over half of study participants were concerned about the low quality of services in SHI-registered hospitals/clinics. Historically, HIV services in Vietnam have been provided through the preventive medicine system. To decentralize the HIV service delivery system, the Ministry of Health has encouraged prevention-focused facilities to sign contracts with the VSS to allow provision of and reimbursement for HIV/AIDS curative services through the SHI fund [5]. However, HIV patients do not yet trust the quality of health services at the new local facilities that have signed contracts with the VSS. Like our study participants, many PLHIV have been receiving ART at urban hospitals for a long time, and their VL has been successfully controlled [29]. In this context, it is easy to understand that PLHIV worry about being transferred to lower-level facilities just for political reasons, rather than to meet their own needs.

In the present study, many participants showed a willingness to regularly visit NHTD after being transferred to SHI-registered hospitals/clinics. This suggests that strengthening links between higher-level and lower-level facilities to continuously transfer knowledge and techniques for HIV treatment and care is a possible way to ensure the good quality of HIV services at all levels and to mitigate patients' worries and anxieties. Although NHTD and other large HIV clinics have been organizing HIV training courses for medical doctors who have just started providing HIV treatment, these are mainly classroom lectures based on project-based grants from international organizations. The Vietnamese Ministry of Health must show stronger leadership to establish an effective hospital network to promote technical assistance in more systematic and practical ways. This would certainly help to achieve 90-90-90 targets in Vietnam.

\section{Factors associated with concerns about decentralization}

We found that female and older ( $\geq 40$ years old) participants were more likely to report concerns about the decentralization of HIV services. Considering the influence of gender roles on childbearing, women are more likely to be concerned about influences on their children [30]. Indeed, some participants reported that "It will influence my child's school life" and "It will stress my children." Alternatively, the association between older age and having concerns about decentralization might be partly explained by the double stigma of HIV and ageism (i.e., patients are recognized as being too old to have HIV) and higher demands on the quality of health services to address multiple health complications [31]. Considering that women and older people are more likely to develop psychiatric disorders such as depression [32, 33] and anxiety [34, 35], which may be triggered by loneliness or social isolation [36, 37], more attention should be paid to their unique needs to prevent mental illness in these groups.

\section{Strengths and limitations}

A strength of the present study is the uniqueness of the data, which reflect patients' voices about the current HIV financial and service transition obtained from one of the largest HIV patient cohorts in Vietnam, with a response rate of $100 \%$. These findings could contribute to the development of strategies based on patients' perspectives to successfully implement the decentralized HIV service delivery using the SHI fund. However, a few limitations should be acknowledged. First, as this was a single-center study, the participants who were receiving HIV services at a central urban hospital may not be 
representative of Vietnam's entire HIV population. Second, we used a cross-sectional design, which limits the extent to which causal inferences can be drawn for the associations identified. Third, as the purpose of the survey was to urgently assess the needs of HIV patients, the response options that we generated may have been too narrow to fully reflect their opinions. However, these responses were selected based on previous reports and experts' opinions about HIV in Vietnam.

\section{Conclusions}

Although SHI coverage has been rapidly progressing, most patients are concerned about disclosure of their HIV status and the quality of services at lower-level facilities, and are willing to maintain contact with their current hospital. In response to their voiced concerns, the establishment of a hospital network to strengthen the links between higher-level and lower-level facilities could facilitate good quality HIV services at all levels, mitigate patients' worries and anxieties, and help to achieve the 90-90-90 targets in Vietnam.

\section{Abbreviations}

95\% Cl: 95\% confidence interval; ART: Antiretroviral therapy; IDU: Injection drug use; NHTD: National Hospital for Tropical Diseases; OR: Odds ratio; PEPFAR: The United States' President's Emergency Plan for AIDS Relief; PLHIV: People living with HIV; SHI: Social health insurance; VL: Viral load; VSS: Vietnam Social Security

\section{Acknowledgments}

We wish to thank Ms. Huyen Thi Nguyen and Ms. Mika Sata for their help and support with data management. We also gratefully acknowledge all the staffs and patients in the HIV outpatient clinic at NHTD for their contribution.

\section{Authors' contributions}

SM, JT, DM, and SO conceived and designed the study. SM, HDTN, DTN, TVG, and KVN collected and analyzed the data. SM wrote the paper. All authors have read and approved the manuscript.

\section{Funding}

This research was supported by the Japan Agency for Medical Research and Development (AMED) under Grant Number 19 fm0108001 (Japan Initiative for Global Research Network on Infectious Diseases (J-GRID)). This funding source had no role in study design, data collection, data analysis and interpretation, and manuscript writing.

\section{Availability of data and materials}

Not applicable.

\section{Ethics approval and consent to participate}

The study was approved both by the Human Research Ethics Committee of the National Center for Global Health and Medicine (reference: NCGM-G002537-01) and by the Bio-medical Research Ethics Committees of National Hospital for Tropical Diseases (reference:08/HDDD-NDTU). We performed this study in accordance with the Japan Ethical Guidelines for Medical and Health Research Involving Human Subjects issued by the Japanese Ministry of Health, Labour and Welfare. Each participant provided written informed consent.

\section{Consent for publication}

Not applicable.

\section{Competing interests}

The authors declare that they have no competing interests.

\section{Author details}

1'AIDS Clinical Center, National Center for Global Health and Medicine, 1-21-1, Toyama, Shinjuku, Tokyo 162-8655, Japan. ${ }^{2}$ National Hospital for Tropical Diseases, Hanoi, Vietnam. ${ }^{3}$ Hanoi Medical University, Hanoi, Vietnam.

Received: 30 July 2019 Accepted: 30 December 2019

Published online: 10 January 2020

\section{References}

1. UNAIDS: Counry SNAPSHOT Viet Nam. 2018. https://www.aidsdatahub.org/ sites/default/files/country_review/Niet_Nam_Country_Card_2018_sep.pdf. Accessed 13 June 2019.

2. The Vietnam Ministry of Health: Optimizing Viet Nam's HIV Response: An Investment Case. 2014. https://www.aidsdatahub.org/sites/default/ files/publication/Vietnam_investment_case_2014.pdf. Accessed 14 Nov 2019.

3. The World Bank: Moving Toward Universal Coverage of Social Health Insurance in Vietnam. 2014. http://documents.worldbank.org/curated/en/3 83151468138892428/Moving-toward-universal-coverage-of-social-healthinsurance-in-Vietnam-assessment-and-options. Accessed 14 Nov 2019.

4. The Vietnam Social Security: VSS's achievements by January 2019. 2019. https://vss.gov.vn/english/research/Pages/statistics.aspx?CatelD=202 \&ltemID=8706. Accessed 14 Nov 2019.

5. Todini N, Hammett TM, Fryatt R. Integrating HIV/AIDS in Vietnam's social health insurance scheme: experience and lessons from the health finance and governance project, 2014-2017. Health Syst Reform. 2018:4:114-24.

6. UNAIDS: Towards Universal Health Coverage in Viet Nam: Meeting the needs of people affected by HIV. http://unaids.org.vn/en/towards-universalhealth-coverage-in-viet-nam-meeting-the-needs-of-people-affected-by-hiv/. Accessed 13 June 2019.

7. Nguyen LH, Hoang ATD. Willingness to pay for social health Insurance in Central Vietnam. Front Public Health. 2017;5:89.

8. VietNam Network of People Living with HIV (VNP+): Stigma Index. 2015. http://www.stigmaindex.org/sites/default/files/reports/Vietnam\%202015\%2 Oreport\%20Stigma\%20Index\%20R2\%20Report\%20Eng.pdf . Accessed 13 June 2019.

9. Tran BX, Than PQT, Tran TT, Nguyen CT, Latkin CA. Changing sources of stigma against patients with HIV/AIDS in the rapid expansion of antiretroviral treatment Services in Vietnam. Biomed Res Int. 2019:2019: 4208638.

10. The Viet Nam Administration of HIV/AIDS Control (VAAC), The Vietnam Ministry of Health, UNAIDS: Social Health Insurance and People Living with HIV in Viet Nam, An assessment of enrollment in and use of social health insurance for the care and treatment of people living with HIV. 2015. http:// unaids.org.vn/wp-content/uploads/2017/01/SHI-report-layout_En_Final.pdf. Accessed 14 Nov 2019.

11. Nguyen QLT, Van Phan T, Tran BX, Nguyen LH, Ngo C, Phan HTT, Latkin CA. Health insurance for patients with HIV/AIDS in Vietnam: coverage and barriers. BMC Health Serv Res. 2017;17:519.

12. The General Statistics Office of Viet Nam: Monthly average income per capita at current prices by income quintile and by province. 2012. https:// www.gso.gov.vn/default_en.aspx?tabid=783. Accessed 14 Nov 2019.

13. The United Nations: UNdata, Vietnam. 2018. http://data.un.org/en/iso/vn. html. Accessed 14 Nov 2019.

14. Remme M, Siapka M, Sterck O, Ncube M, Watts C, Vassall A. Financing the HIV response in sub-Saharan Africa from domestic sources: moving beyond a normative approach. Soc Sci Med. 2016;169:66-76.

15. Kaiser Family Foundation, UNAIDS: Donor Government Funding for HIV in Low- and Middle-Income Countries in 2016. https://www.unaids.org/sites/ default/files/media_asset/20170721_Kaiser_Donor_Government_Funding_ HIV.pdf. Accessed 19 June 2019.

16. UNAIDS: FACT SHEET, global HIV statistics. 2019. https://www.unaids.org/ sites/default/files/media_asset/UNAIDS_FactSheet_en.pdf. Accessed 14 Nov 2019.

17. Olakunde BO, Ndukwe CD. Improved domestic funding enhances the sustainability of HIV/AIDS response in Nigeria. Ann Glob Health. 2015;81: 684-8.

18. The Viet Nam Administration of HIV/AIDS Control (VAAC). Vietnam Authority of HIV/AIDS Control Report: Barriers to access to health insurance among people living with HIV/AIDS. 2016. 
19. Agago TA, Woldie M, Ololo S. Willingness to join and pay for the newly proposed social health insurance among teachers in Wolaita Sodo town South Ethiopia. Ethiop J Health Sci. 2014;24:195-202.

20. Matsumoto S, Yamaoka K, Takahashi K, Tanuma J, Mizushima D, Do CD, Nguyen DT, Nguyen HDT, Nguyen KV, Oka S. Social support as a key protective factor against depression in HIV-infected patients: report from large HIV clinics in Hanoi, Vietnam. Sci Rep. 2017;7:15489.

21. Gaudine A, Gien L, Thuan TT. Dung do V: perspectives of HIV-related stigma in a community in Vietnam: a qualitative study. Int J Nurs Stud. 2010;47:3848.

22. Thi MD, Brickley DB, Vinh DT, Colby DJ, Sohn AH, Trung NQ. Giang le T, Mandel JS: a qualitative study of stigma and discrimination against people living with HIV in Ho Chi Minh City, Vietnam. AIDS Behav. 2008;12:S63-70.

23. Thanh DC, Moland KM, Fylkesnes K. Persisting stigma reduces the utilisation of HIV-related care and support services in Viet Nam. BMC Health Serv Res. 2012;12:428.

24. Roura M, Wringe A, Busza J, Nhandi B, Mbata D, Zaba B, Urassa M. "Just like fever": a qualitative study on the impact of antiretroviral provision on the normalisation of HIV in rural Tanzania and its implications for prevention. BMC Int Health Hum Rights. 2009;9:22.

25. UNAIDS: Confronting discrimination; overcoming HIV-related stigma and discrimination in healthcare settings and beyond. 2017. https://www.unaids. org/sites/default/files/media_asset/confronting-discrimination_en.pdf. Accessed 21 June 2019.

26. Stangl AL, Lloyd JK, Brady LM, Holland CE, Baral S. A systematic review of interventions to reduce HIV-related stigma and discrimination from 2002 to 2013: how far have we come? J Int AIDS Soc. 2013;16:18734.

27. Sengupta S, Banks B, Jonas D, Miles MS, Smith GC. HIV interventions to reduce HIV/AIDS stigma: a systematic review. AIDS Behav. 2011;15:1075-87.

28. Brown L, Macintyre K, Trujillo L. Interventions to reduce HIV/AIDS stigma: what have we learned? AIDS Educ Prev. 2003;15:49-69.

29. Tanuma J, Matsumoto S, Haneuse S, Cuong DD, Vu TV, Thuy PTT, Dung NT, Dung NTH, Trung NV, Kinh NV, Oka S. Long-term viral suppression and immune recovery during first-line antiretroviral therapy: a study of an HIVinfected adult cohort in Hanoi, Vietnam. J Int AIDS Soc. 2017;20(4).

30. Paudel V, Baral KP. Women living with HIV/AIDS (WLHA), battling stigma, discrimination and denial and the role of support groups as a coping strategy: a review of literature. Reprod Health. 2015;12:53.

31. Emlet CA. "You're awfully old to have this disease": experiences of stigma and ageism in adults 50 years and older living with HIV/AIDS. Gerontologist. 2006:46:781-90.

32. Meagher D, Murray D. Depression. Lancet. 1997;349(Suppl 1):S117-20

33. Kok RM, Reynolds CF 3rd. Management of Depression in older adults: a review. JAMA. 2017:317:2114-22.

34. McLean CP, Asnaani A, Litz BT, Hofmann SG. Gender differences in anxiety disorders: prevalence, course of illness, comorbidity and burden of illness. J Psychiatr Res. 2011;45:1027-35.

35. Hellwig S, Domschke K. Anxiety in Late Life: An Update on Pathomechanisms. Gerontology. 2019;65(5):465-73.

36. Ge L, Yap CW, Ong R, Heng BH. Social isolation, loneliness and their relationships with depressive symptoms: a population-based study. PLoS One. 2017;12:e0182145.

37. Richard A, Rohrmann S, Vandeleur CL, Schmid M, Barth J, Eichholzer M. Loneliness is adversely associated with physical and mental health and lifestyle factors: results from a Swiss national survey. PLoS One. 2017;12: e0181442.

\section{Publisher's Note}

Springer Nature remains neutral with regard to jurisdictional claims in published maps and institutional affiliations.

Ready to submit your research? Choose BMC and benefit from:

- fast, convenient online submission

- thorough peer review by experienced researchers in your field

- rapid publication on acceptance

- support for research data, including large and complex data types

- gold Open Access which fosters wider collaboration and increased citations

- maximum visibility for your research: over $100 \mathrm{M}$ website views per year

At $\mathrm{BMC}$, research is always in progress.

Learn more biomedcentral.com/submissions 